\title{
Quality of Life in Iranian Breast Cancer Survivors and Affecting Factors: A Review Article
}

\author{
Mohammad-Reza Zaker, Afshin Hazrati-Marangaloo, Seyede-Roghayeh Hosseini
}

MSc in Nursing, Intensive Care Nursing, School of Allied Medical Sciences, Urmia University of Medical Science, Urmia, Iran.

\begin{abstract}
Introduction: The breast cancer is the first common cancer among Iranian women, accounting for $24.4 \%$ of all cancers. With the improvement in disease-free survival with advanced treatment modalities, question of quality of life (QOL) arises. The aim of the present review was assessment QOL of Iranian women with cancer breast and affecting factors. Methods: This study is a review article in which articles about Breast cancer were searched in databases such as Scopus, SID, Magiran, Google Scholar, Pubmed, IranMedex, ScienceDirec from key words of Cancer Brest, Quality of Life, Affecting Factor and Iran were used to search. Results: Twenty-eight studies from 2008 to 2018 on the quality of life of 2226 patients with breast cancer in Iran were conducted. In these studies, five different questionnaires QLQ-C30, SF-36, Ferrans \& Power, QLQ-BR23, WHO-QOL 26 to check the quality of life patients were used. Conclusion: Breast cancer affects the quality of life of the patients and reduces it. Psychological and financial support and exercise and health for women experiencing breast cancer diagnosis can have been a positive impact on the disease and the patient's compliance with the complications of the disease and the treatments.
\end{abstract}

Keywords: Cancer Brest- quality of life- affecting factor and Iran

Asian Pac J Environment and Cancer, 2 (1), 5-9

\section{Introduction}

Breast cancer is the most common cancer diagnosed among United States (US) women (excluding skin cancer) and is the second leading cause of cancer death among women after lung cancer [1]. According to breast cancer statistics, in the US, 252,710 women with breast cancer, which is $30 \%$ of all cancers [2]. In Iran also, breast cancer is the first common cancer among women, accounting for $24.4 \%$ of all cancers [3]. Overall breast cancer death rates increased by $0.4 \%$ per year from 1975 to 1989 but since have decreased rapidly, for a total decline of $39 \%$ through 2015. Decline in breast Cancer mortality rates have been attributed to both improvements in treatment and early detection by mammography [4]. Most of these treatments are complicated and have serious side effects that affect the physical, psychological and social aspect of the patients, life and can significantly reduce the quality of life (QOL) in these patients [5]. Chemotherapy, an adjuvant therapy, is commonly applied to most patients with breast cancer and has contributed to the increase in cancer
Submission Date: 01/05/2019 Acceptance Date: 03/07/2019

survival rates. However, chemotherapy leads to various physical symptoms (e.g., vomiting, hair loss, pain, and fatigue) and psychological distress (e.g., depression and anxiety)[6]. With the improvement in disease-free survival with advanced treatment modalities, question of quality of life (QOL) arises. Most of the health care should be ultimately evaluated in terms of the impact that the therapy has on QOL [7].

Today, quality of life surveys are important issue in health care, especially in oncological research [8]. It has been shown that assessing quality of life in cancer patients could contribute to improved treatment [8]. Breast cancer is probably the most feared by women, especially by the negative stigma brought by its diagnosis and due to its psychological effects, which affect the perception of sexuality and their own personal image [7]. Effort to promote the QOL in breast cancer patients is considered as one the most important topics in women's health care [9].

QOL is a subjective phenomenon and there is no generally agreed definition. World Health Organization (WHO) defines QOL as an individual's perception of

Corresponding Author:

Dr. Seyede-Roghayeh Hosseini

MSc in Nursing, Intensive Care Nursing, School of Allied Medical Sciences, Urmia University of Medical Science, Urmia, Iran.

Email: roghayehhosseini31@yahoo.com 
their position in life in the context of culture and value systems in accordance with their goals, aspirations, and standards [10]. QOL generally consists of a number of domains including physical functioning, psychological well-being (such as levels of anxiety and depression), and social support [11]. The aim of the present review is to collect and discuss publications that have appeared between 2008-2018 in English or Persian language for assessment QOL of Iranian women with cancer breast. It is hoped that this assessment may contribute to existing knowledge, provide both researchers and clinicians with a better profile on the topic, and consequently help improve quality of life in breast cancer patients.

\section{Materials and Methods}

This study is a review article in which articles about Breast cancer were searched in databases such as Scopus, SID, Magiran, Google Scholar, Pubmed, IranMedex, ScienceDirect. from key words of Cancer Brest, Quality of Life, and Iran were used to search. Articles were discussed that their main issue in the field of quality of life and the impact of various factors on it were in women with breast cancer in the period of 2008-2018. The articles were analyzed in both English and Persian. According to the keywords, 28 articles were included in the study. The articles were arranged in order of importance and relevance to the topic, and sections of each article that could be used were identified. The strengths and weaknesses of each memo article and a comprehensive compilation of articles was performed.

\section{Results}

Twenty-eight studies from 2008 to 2018 on the quality of life of 2226 patients with breast cancer in Iran were conducted. In these studies, five different questionnaires QLQ-C30, SF-36, Ferrans \& Power, QLQ-BR23, WHO-QOL 26 to check the quality of life patients were used. In 6 out of 28 studies, quality of life was expressed in terms of percentages that in the study of Mohaddesi et al $71.4 \%$ of patients had good quality of life and the lowest percentage related to quality of life was related to the study of Kabiri et al. In the study of Mirzaie et al., $51 \%$ had poor quality of life in the study of Kabiri et al this value was zero. In 22 other studies, of the score was used to express the quality of life. The most questionnaire used in these studies was QLQ-C30 questionnaire (18 studies). The mean score of quality of life in 18 studies was $78 \pm 20.06$. The highest score of quality of life $(94.3 \pm 12.98)$ was related to the study of Akbari et al. And the lowest score was related to Rahimi's study.

\section{Discussion}

Cancer disease is an extremely unpleasant and unbelievable experience for any person which can cause problems in a state of life, work and mental health of a person and cause that the quality of life a person in different dimensions will be difficult. In this regard, many studies have been conducted on the quality of life that has had an association with the severity and type of disease, and this study has been conducted to assess the quality of life and affecting factors in people with breast cancer in Iran.

$Q O L$

There is no relationship between demographic variables and quality of life in the studies of Kabiri et al. [12] and Mohaddesi et al [13]. In a study conducted by Dehestani et al [14]. there is a direct relationship between level of education and quality of life. QOL in women survived and those suffered from breast cancer while under chemotherapy was low [15], and QOL in $36.3 \%$ of patients was evaluated as good [16]. Ihe result of study by Sehati Shafaee the mean total score of the quality of life was $59.1 \pm 17.4$ in the women, ranging from zero to 100. The highest mean score was obtained in the cognitive subscale (74.9 \pm 23.8$)$ and the lowest in the emotional subscale $(51.4 \pm 21.1)$ [17]. In studies conducted by Dehestani [14] and Alagheband [18] and Karimi [19], the highest quality of life was observed in general health. And also in a study conducted by Dehestani [14] and Mirzaei et al. [20] the lowest level of quality of life has been seen in the psychological aspect that this result could be due to the mental impairment of the body and the persistent mental stress of the individual due to the disease. Another study has shown he best functional outcomes were found for the cognitive and social functioning subscales and emotional functioning scored the lowest. Breast cancer patients were suffered from insomnia, fatigue and pain. Other symptoms such as diarrhea, constipation, dyspnea, nausea and vomiting and appetite loss were reported less severity [21]. The results of Montazeri study at eighteen months follow-up data for 99 patients has shown physical functioning was improved following one year after the completion of breast cancer treatmen but another dimension of QOL were lower at 18 months follow-up than baseline and 3 months assessments [22]. A study conducted by the Dehestani et al [14] has shown that increasing the number of chemotherapy sessions has led to an increase and improvement in the quality of life in people with breast cancer, and this result can be due to increased compliance of the individual with the disease and compliance with chemotherapy drugs and Its complications were increased by sessions.

\section{Support and $Q O L$}

In a study conducted by Mohaddesi et al [13] and Safaee et al [21] as well as Hatam et al [23], psychological, social and economic support have led to an increase in the quality of life that can result in a positive psychological effect of family and children's support as well as the patient's lack of concern about the cost of treatment. In Javadian Kotenaie study [16], The worst condition was related to the economic impact of the QOL with $25 \%$ of patients suffering from this condition. In a study conducted by Hosseini et al [24], having children has reduced the quality of life, which can be due to the disappointment of a person and the feeling of not being helpful. 


\section{Education and QOL}

In a study conducted by Mohaddesi et al [13]. Participation in educational classes and palliative care services has led to a rise in quality of life in the role play of the dimensions of quality of life that Mirzaei [20] and Alagheband [18] have both concluded in their research, and this can be due to increased awareness of the disease and The consequences were. A study conducted by shirvani et al [25]. Has shown that nurses play a role in improving the quality of life of people with breast cancer, which can be attributed to appropriate nursing education by nurses managers. A study by Ghanbari et al [26]. Has shown that a pamphlet by educational modules designed to improve the quality of life of people with breast cancer, which can result from providing comprehensive information on the disease and its complications and methods of coping with physical and psychological problems in the disease.

\section{Mental and physical health and $Q O L$}

In a study conducted by Alagheband [18] it has been shown that mental health improves the quality of life that can be due to positive thinking and appropriate social relationships. In a study conducted by Shafiee tabar, [27] it was concluded that psychological intervention has led to an increase in the quality of life in people with cancer, which could be due to a greater control over life conditions. Also in the dimension of physical function, Suitable physical function also improves the quality of life in these individuals because it increases the incidence of cancer compatibility and complications as an intervention. In the area of social performance, a study conducted by Shafiee tabar has shown that cancer has reduced social function, which can be due to complications from cancer and the presence of physical and psychological problems. In a study conducted by Mohaddesi et al [13], has been shown fatigue reduce the quality of life of patients, which may be due to lack of follow-up treatment by people with cancer or fatigue due to complications. A study conducted by Naghipoor [28] has shown that in the context of sexual relations, cancer also has the potential to reduce sexual intercourse and thus reduce the quality of life that can be due to physical exhaustion due to cancer. Impaired body image decreased sexual functioning and sexual enjoyment in patients must be seriously considered in long-term survivors of breast cancer to improve their overall quality of life [22].

A study conducted by Naghipoor et al [28]. Showed that the presence of pain in people with breast cancer, which caused a decrease in quality of life and a reduction in body image, also led to a decrease in quality of life in these people, which could be due to the lack of consideration of welfare dimensions Patients. The results have demonstrated that stress management has major influence on the quality of life in breast cancer patients [29].

\section{Religious and $Q O L$}

It has also been concluded that the existence of religious beliefs improves the quality of life in people with cancer, which can be due to the purposefulness of the life of religious people. A study conducted by Karimi et al [19] showed that religious and spiritual beliefs can improve the quality of life in people with breast cancer, which could be the result of the use of spiritual capital to solve spiritual problems. In the another study total scores and all subscales scores for QOL were significantly higher in patients with high religiosity than patients with moderate religiosity and a significant relationship was found between religiosity and QOL in patients with breast cancer [30].

\section{Care and $Q O L$}

The research carried out by Afrasiabi far et al. [31] has shown that orem self-care program has been able to improve the quality of life of people with breast cancer, which can be attributed to self-care education by nurses to affected people. Statistical test showed that in the intervention group immediately before and after 3 months from performing self-care education, there is a statistically significant difference between average score of physical dimension of QOL, psychological dimension of QOL, social dimension of QOL, spiritual dimension of QOL, and total score of QOL [32]. The Qol of breast cancer survivors who had attended rehabilitation programs such as physiotherapy, education and counseling had been much better than those who had not attended these programs [33]. A study conducted by Adili et al. [34] concluded that lack of time in caregivers for caring of patients had correlation with QOL.

\section{Exercise and $Q O L$}

A study conducted by Sabaghi et al [35]. Has shown that Swedish exercises have improved the quality of life of survivors of breast cancer, resulting in a reduction in the sense of fatigue and mental fatigue due to Swedish exercise. In a study conducted by Zareian et al [36], It has been shown that aerobic exercises have improved the quality of life of people with breast cancer, which could be due to the reduction of anxiety and depression due to aerobic movements. The result of Shobeyri study showed functional scales of exercise counseling had a positive effect on the quality of life of women with breast cancer, and led to a significant improvement in patients [37].

In conclusion, with considering this fact that, different types of cancer including breast cancer always considered as major health problems, diverse managment and treatment strategies were used to overcome cancer [38-42]. Since breast cancer affects the quality of life of the patients and reduces it. Psychological and financial support for women experiencing breast cancer diagnosis may improve QOL. Therefore, affecting factors like exercise, increasing spiritual health can have been a positive impact on the disease and the patient's compliance with the complications of the disease and the treatments. 


\section{References}

1. Breast cancer Facts \& Figures. 2017; [cited]; Available from: $\mathrm{http} / /$. cancer.org/statistics.

2. Siegel RL, Miller KD, Jemal A. Cancer Statistics, 2017. CA CANCER J CLIN 2017;67:7-30.

3. Ranjkesh M, Azar FF, Samani FG-, Tarzamni M, Vali-Khani E. Evaluation of adjunctive sonography results in screening of women with mammographically dense breasts for early diagnosis of breast cancer. Iran J Breast Dis. 2017;10(7-19).

4. Munoz D, Near A, Ravesteyn N. Effects of screening and systemic adjuvant therapy on ER-specific US breast cancer mortality. J Natl Cancer Inst. 2014;106:289.

5. Oh P-J, Cho J-R. Changes in Fatigue, Psychological Distress, and Quality of Life After Chemotherapy in Women with Breast Cancer. Cancer Nursing. 2018;00(0):1-7.

6. Kim S, Lee R, . KL. Symptom clusters in patients with breast cancer. Korean J Adult Nurs. 2009;21(6):705-17.

7. Sharma N, Purkayastha A. Factors Affecting Quality of Life in Breast Cancer Patients: A Descriptive and Cross-sectional Study with Review of Literature Journal of Mid-life Health. 2017;8(2):75-83.

8. Paraskevi T. Quality of life outcomes in patients with breast cancer. Oncology Reviews 2012;6(e2):7-10.

9. Shandiz FH, Karimi F-Z, Khosravi Z, Abdollahi M, Rahimi $\mathrm{N}$, Ghasemi M. Investigating the Quality of Life and the Related Factors in Iranian Women with Breast Cancer. Asian Pac J Cancer Prev. 2017;18(8):2089-92.

10. Alipour F, Sajadi H, Foruzan A, Biglarian A, Jalilian A. Elderly quality of life in Tehran's district two. Iran J Ageing. 2008;3(3):75-83.

11. Perry S, Kowalski TL, Chang C-H. Quality of life assessment in women with breast cancer: benefits, acceptability and utilization. http://wwwbiomedcentralcom/.2007;5(24):1-14.

12. Kabiry B, Pournajaf A, Lotfei AHM, Kazemi A. The Relationship between Mental Health and Life Quality in Cancer Patients in Ilam Province in 2014. Scientific Journal of Ilam University of Medical Sciences. 2016;25(2):1-7.

13. Mohaddesi H, Ayatollahi H, Hassanzadeh G, Yegansangi M. Quality of life in breast cancer patients: Study in the Omid cancer research center-Urmia. Iranian Quarterly Journal of Breast Diseases. [Research]. 2013;5(4):35-43.

14. Dehestani M, Bagherian M, Musarezaie A. The Predictive Role of Psychological, Medical and Demographic Factors on Quality of Life in Patients with Breast Cancer. J Res Behave Sci. 2014;12(4):6-12.

15. Moghani MM, Peykani S, Amani O. Comparative study of quality of life in women survived and those suffered from breast cancer while under chemotherapy. Journal of Health of Promotion management. 2017;7(2):8-13.

16. Javadian-Kotenaie M, Akram S, Bouzari Z, Yazdani S. Evaluation of Quality of Life and Menopausal Symptoms in Women with Breast Cancer in Northern Iran. Int Biol Biomed J. 2015;1(2):84-9.

17. Shafaee FS, Mirghafourvand M, Harischi S, Esfahani A, Amirzehni J. Self-Confidence and Quality of Life in Women Undergoing Treatment for Breast Cancer. Asian Pac J Cancer Prev. 2018;19(3):733-40.

18. Alagheband M, Servat F, Zarepour F. Investigation of the Relationship between Quality of Life and Life Expectancy in Patients with Breast Cancer. Tolooebehdasht. [Research]. 2016;15(2):175-85.

19. mohamad karimi m, shariatnia k. Effectiveness of Spiritul Therapy on the Life Quality of the Women with Breast Cancer in Tehran. Journal of Nursing and Midwifery Urmia University of Medical Sciences. [Research].
2017;15(2):107-18.

20. Mirzaei H, Mostafaei D, Estebsari F, Sattarzadeh M, Estebsari K. The Quality of Life of Breast Cancer Patients Receiving Palliative and Supportive Care. Iranian Journal of Rehabilitation Research in Nursing. [Research]. 2017;3(2):19-26.

21. Safaee A, Moghimi-Dehkordi B, Zeighami B, Tabatabaee $\mathrm{H}$, Pourhoseingholi M. Predictors of quality of life in breast cancer patients under chemotherapy. Indian Journal of Cancer. 2008;45(3):107-11.

22. Montazeri A, Vahdaninia M, Harirchi I, Ebrahimi M, Khaleghi F, Jarvandi S. Quality of life in patients with breast cancer before and after diagnosis: an eighteen months follow-up study. BMC Cancer. 2008;8(330):2-6.

23. Hatam N, Bastani P, Ahmadlo N, Ahmadkia-Daliri AA. Health Related Quality of Life in Breast Cancer Patients Undergoing Current Chemotherapy Protocols. Journal of Kerman University of Medical Sciences. 2011;18(1):49-58.

24. Hosseini SM. Quality of life, pain and treatment acceptance in women with breast cancer in Chaharamahal and Bakhtiari. Iranian Quarterly Journal of Breast Diseases. [Research]. 2014;6 (4):52-9.

25. Shirvani H, Alhani F, Montazeri A. The Effect of Familycentered Empowerment Model on the Functional Scales Quality of Life in Women with Breast Cancer Undergoing Chemotherapy. Iranian Quarterly Journal of Breast Diseases. [Research]. 2017;10 (1):61-72.

26. Ghanbari S. Survey of the effect of Occupational Therapy program pamphlet on Quality of Life in women with Breast Cancer. Iranian Quarterly Journal of Breast Diseases. [Research]. 2013;6 (2):43-9.

27. Shafietabar M, Khodapanahi MK, Heidari M. The Effectiveness of a Psycho-Educational Intervention in Improving the Quality of Life of Patients with Breast Cancer. Scientific Journal Management System. 2013;9(36):351-71.

28. Naghipoor L, Zare-bahramabadi M, Taghiloo S, Heidari H. Comparison of body image, sexual satisfaction and quality of life in women with breast cancer. Women's Strategic Studies. 2012;10(4):41-62.

29. Khodabakhshi-Koolaee A, Falsafinejad M-R, Akbari M-E. The Effect of Stress Management Model in Quality of Life in Breast Cancer Women. Iran J Cancer Preven. 2015;8(4):1-6.

30. Zargani A, Nasiri M, Hekmat K, Abbaspour Z, Vahabi S. A Survey on the Relationship between Religiosity and Quality of Life in Patients with Breast Cancer: A Study in Iranian Muslims. Asia Pacific Journal of Oncology Nursing. 2018;5(2):217-22.

31. Afrasiabifar A, Hamzhiekia S, Hosseini N. The effect of Self-Care Program Using Orem's Self- Care Model on the Life Quality of Women with Breast Cancer Undergoing Chemotherapy: A Randomized Controlled Trial. Armaghane danesh. [Research]. 2018;23(1):1-13.

32. Shahsavari H, Matory P, Zahra Zare FT, Kaji MA. Effect of self-care education on the quality of life in patients with breast cancer. Journal of Education and Health Promotion 2015;4:1-6

33. Poorkiani M, Abbaszadeh A, Hazrati M, Jafari P, Sadeghi M, Mohammadianpanah $\mathrm{M}$. The effect of rehabilitation on quality of life in female breast cancer survivors in Iran. Indian Journal of Medical and Paediatric Oncology. 2010;31(4):105-9.

34. Adili D, Dehghani-Arani F. The relationship between caregiver's burden and patient's quality of life in women with breast cancer. Journal of Research in Psychological Health. 2018;10(2):30-9.

35. Sabaghi Kenari M, Hadadnezhad M, Karimi M. Effect of 
Callisthenic Exercises on Shoulder Range of Motion, Pain and Quality of Life on Female Breast Cancer Survivals. Iranian Quarterly Journal of Breast Diseases. [Research]. 2017;9(4):60-70.

36. Zareian E, Rahmati F. Effect of Aerobic exercise on anxiety, depression and quality of life in women with breast cancer. Clinical Psychology Studies. 2014;5(17):1-18.

37. Shobeyri F, Nikravesh A, Masoumi SZ, Heydari-Moghadam R, Karami M, Badafreh M. Effect of Exercise Counseling on Functional Scales Quality of Life in Women with Breast Cancer. Journal of Education and Community Health. 2015;2(1):1-9.

38. Mohamadi N, Kazemi SM, Mohammadian M, et al. Toxicity of Cisplatin-Loaded Poly ButylCyanoacrylate Nanoparticles in a Brain Cancer Cell Line: Anionic Polymerization Results. Asian Pac J Cancer Prev. 2017;18(3):629-632.

39. Arshad Z, Rezapour-Firouzi S, Mohammadian M, Ebrahimifar. The Sources of Essential Fatty Acids for Allergic and Cancer Patients; a Connection with Insight into Mammalian Target of Rapamycin: A Narrative Review. Asian Pac J Cancer Prev. 2018;19(9):2391-2401.

40. Mohammadian M, Zeynali S, Azarbaijani AF, Khadem Ansari MH, Kheradmand F. Cytotoxic effects of the newlydeveloped chemotherapeutic agents 17-AAG in combination with oxaliplatin and capecitabine in colorectal cancer cell lines. Res Pharm Sci. 2017;12(6):517-525.

41. Zeynali-Moghaddam S, Mohammadian M, Kheradmand F, Fathi-Azarbayjani A, Rasmi Y, Esna-Ashari O, Malekinejad H. A molecular basis for the synergy between 17 allylamino 17 demethoxy geldanamycin with Capecitabine and Irinotecan in human colorectal cancer cells through VEFG and MMP-9 gene expression. Gene. 2019 Feb 5;684:30-38.

42. Izadi M, Ebrahimi Shahemabadi H, Kanaani L, et al (2016). Investigation of characteristics of loaded carboplatin on the liposomal nanoparticles on the cell carcinoma of the human brain c6. Adv. Biores, 7, 113-118.

\section{(1) $\Theta$}

This work is licensed under a Creative Commons AttributionNon Commercial 4.0 International License. 